\title{
Uma nova espécie de Passiflora L. (Passifloraceae) para o Brasil ${ }^{1}$
}

\author{
Teonildes Sacramento Nunes ${ }^{2,3}$ e Luciano Paganucci de Queiroz ${ }^{2}$
}

Recebido em 8/05/2006. Aceito em 13/11/2006

\begin{abstract}
RESUMO - (Uma nova espécie de Passiflora L. (Passifloraceae) para o Brasil). Uma nova espécie de Passifloraceae é descrita e ilustrada, Passiflora mucugeana T.S. Nunes \& L.P. Queiroz. Esta espécie é conhecida até o momento, na região da Chapada Diamantina, Bahia, em áreas próximas aos municípios de Mucugê, Ibicoara e Barra da Estiva, em áreas de florestas estacionais e campo rupestre (Complexo Espinhaço), chegando a uma altitude de 1.200 metros. Passiflora mucugeana é inserida no subg. Passiflora supersect. Stipulata Feuillet \& MacDougal sect. Granadillastrum Triana \& Planch., por apresentar caracteres morfológicos que a assemelham a P. imbeana Sacco.
\end{abstract}

Palavras-chave: Passiflora mucugeana, Passifloraceae, Bahia, Brasil

\begin{abstract}
A new species of Passiflora L. (Passifloraceae) from Brazil). A new Brazilian species of Passifloraceae is described and illustrated: P. mucugeana T.S. Nunes \& L.P. Queiroz. This species is from the Chapada Diamantina region, state of Bahia, near the towns of Mucugê, Ibicoara and Barra da Estiva, growing in semideciduous forests and "campo rupestre", at $1200 \mathrm{~m}$ altitude. The new species is classified in subg. Passiflora supersect. Stipulata Feuillet \& MacDougal sect. Granadillastrum Triana \& Planch., because it appears to be a close relative of $P$. imbeana Sacco.
\end{abstract}

Key words: Passiflora mucugeana, Passifloraceae, Bahia, Brazil

\section{Introdução}

As Passifloraceae são predominantemente tropicais e subtropicais, com cerca de 20 gêneros e 650 espécies (Killip 1938; Cervi 1997; Ulmer \& MacDougal 2004). Ocorrem nas áreas mais quentes da América com algumas espécies na Ásia e Austrália e uma espécie em Madagascar. No Brasil ocorrem quatro gêneros, Mitostemma Mast., Dilkea Mast., Ancisthrothyrsus Harms e Passiflora L., com cerca de 120 espécies, a maioria subordinada ao gênero Passiflora (Killip 1938). O gênero Passiflora subg. Passiflora apresenta cerca de 400 espécies de distribuição pantropical, a maioria nas Américas, sendo o Brasil e a Colômbia os países com maior número de espécies (Cervi 1997). Na Bahia, o gênero é representado por 31 espécies, com distribuição ampla, ocorrendo em praticamente todos os biomas do Estado (Nunes \& Queiroz 2006). Caracteriza-se por apresentar gavinhas axilares, nectários extra-florais no pecíolo foliar, flores com androginóforo e corona de filamentos em uma a várias séries, cinco estames e três carpelos. (Ulmer \& MacDougal 2004). O subgênero Passiflora caracteriza-se por apresentar espécies trepadeiras herbáceas, brácteas inteiras, flores grandes e coloridas, filamentos da corona com duas a várias séries, opérculo encurvado e ovário estreitando-se em direção ao ápice. A supersect. Stipulata sect. Granadillastrum corresponde à antiga série Lobatae (Harms) Killip (Killip 1938; Cervi 1997; Feuillet \& MacDougal 2003).

\section{Resultados e discussão}

Passiflora mucugeana T.S. Nunes \& L.P. de Queiroz, sp. nov. Tipo: BRASIL. Bahia: Ibicoara, nos arredores de Cascável, 1.130 m.s.n.m., 21/III/1999, fl., R.M. Harley et al. 53589 (Holótipo HUEFS, Fotos do holótipo ALCB, CEPEC, K, MBM, RB, SP, UPCB).

Fig. 1-3

Haec species P. imbeana Sacco similis, sed caule non striato, capreolo paulum evoluto, stipulis

1 Parte da dissertação de mestrado da primeira Autora

2 Universidade Estadual de Feira de Santana, Departamento de Ciências Biológicas, Herbário HUEFS, Av. Universitária s/n, 44031-460 Feira de Santana, BA, Brasil

3 Autor para correspondênca: teonildesnunes@yahoo.com.br 
1-1,5×0,8-1 cm (usque ad 2-2,7×0,9-1,9 cm in $P$. imbeana), petiolis cum glandulis duobus binatim prope apicem (usque prope basin in P. imbeana), foliorum paginis abaxialibus opacis et nervo centrali foliorum cum nervis lateralibus angulo $135^{\circ}$ formantis (usque ad $90^{\circ}$ formantis in P. imbeana), bracteis $10 \times 5-8 \mathrm{~mm}$, apice acuto (usque $13 \times 10 \mathrm{~mm}$, apice obtuso in P. imbeana). Flores sepalo dorsali carinato prope apicem (usque ad dorso corniculo brevi praedita in P. imbeana), filamentis coronae 5-seriata (3-seriata in P. imbeana), operculo ad basin plicato filamentoso in medio (usque ad operculo erecto, ad apicem lacerato sub apice filamentoso in P. imbeana), limine androgynophori basin non involventi (in P. imbeana laxa involventi), differt.

Trepadeira escandente, glabra; caule cilíndrico, liso; gavinhas delgadas, pouco desenvolvidas. Estípulas 1-1,5×0,8-1 cm, persistentes, foliáceas, subreniformes, ápice agudo, mucronado, base assimétrica, margem lisa. Pecíolo 1,2-2 cm compr.; 2 glândulas estipitadas, situadas na porção mediana a distal do pecíolo. Lâminas 5,5-7×2,5-3 cm, cartáceas, inteiras quando novas, passando a 3-lobadas, quando maduras, base hastada, subpeltada, margem lisa, levemente revoluta, 2-6 glândulas nos sinus entre os lobos, ou na margem (quando lâminas inteiras); 3-nervadas (obscuramente 5-nervadas), nervura central formando ângulo de $135^{\circ} \mathrm{com}$ as nervuras laterais, avermelhadas, face adaxial lustrosa, face abaxial opaca; lobo central, ou lâmina inteira, lanceolado, ápice agudo, acuminado; lobos laterais, quando presentes, menores que o central, 2,5×2,5-3 cm, ápice agudo, acuminado. Pedúnculo 3-4 cm compr.; brácteas $10 \times 5-8 \mathrm{~mm}$, foliáceas, persistentes, verticiladas, uninérvias, nervuras secundárias reticuladas, oval-lanceoladas, ápice agudo, mucronado, margem lisa. Flores axilares, solitárias, 3-7 cm diâm.; hipanto ca. $1 \mathrm{~cm}$ compr., curto-campanulado, verde-claro; sépalas 20-25x 5-8 $\mathrm{mm}$, carnosas, verdes externamente e com nervuras vináceas, internamente lilases, aristadas, arista emergindo do meio para o ápice da sépala, corniculadas, corno ca. $1 \mathrm{~mm}$ compr.; pétalas 15-20× 5-8 mm, membranáceas, oblongo-lanceoladas, lilases; filamentos da corona em 5 séries, filiformes, lilásescuros, os das séries externas ca. $2 \mathrm{~cm}$ compr., das séries internas ca. $3 \mathrm{~mm}$ compr., com estrias brancas; opérculo membranoso, plicado na base, terminando em filamentos filiformes e margem fimbriada; límen na base do hipanto, cupuliforme, com ápice crenado, não envolvendo a base do androginóforo; disco nectarífero presente; androginóforo ca. $1 \mathrm{~cm}$ compr., reto; filetes e anteras escuros; ovário globoso, com base dilatada, glabro, marrom-esverdeado; estiletes vináceos, livres desde a base; estigmas amarelos, capitados. Frutos e sementes não vistos.

Esta nova espécie foi encontrada em áreas de campo rupestre e matas estacionais, em altitudes variando de 1.000 a 2.200 m.s.n.m. Apresenta características morfológicas que a enquadram no subg. Passiflora L. supersect. Stipulata Feuillet \& MacDougal sect. Granadillastrum Triana \& Planch., a saber: estípulas foliáceas, com a base evidentemente assimétrica e brácteas foliáceas (Feuillet \& MacDougal 2003). Dentre as espécies descritas para esta seção $P$. mucugeana assemelha-se morfologicamente a $P$. imbeana Sacco, descrita para o Estado do Rio de Janeiro (Sacco 1996). Passiflora imbeana diferencia-se de $P$. mucugeana por apresentar caule cilíndrico; gavinhas bem desenvolvidas; pecíolo com 1-2 glândulas estipitadas, situadas abaixo da metade do mesmo; lâminas coriáceas, com ambas as faces lustrosas, nervura principal formando um ângulo de $90^{\circ}$ com as nervuras laterais, ápice arredondado; lobos laterais oval-arredondados e lobo mediano oval; brácteas oval-arredondadas, ápice obtuso, mucronulado; flores com sépalas corniculadas no ápice, corno bem curto, filamentos da corona em três séries; opérculo membranoso, não plicado, com margem lacerada; límen na base do hipanto, cupuliforme, com ápice liso, envolvendo frouxamente a base do androginóforo.

Passiflora mucugeana floresce nos meses de janeiro a março. O período de frutificação ainda não foi devidamente observado.

O epíteto é uma referência ao município de Mucugê na Bahia, onde a espécie foi coletada pela primeira vez, e onde a mesma ocorre em maior abundância.

Parátipos: BRASIL. Bahia: Barra da Estiva, Morro da Antena, campo rupestre, F. França et al. 4327, 5/II/2003 (HUEFS, MBM). Ibicoara, Distrito de Cascável, estrada de chão em direção a Água Fria, mata, 1.072 m s.n.m., T.S. Nunes et al. 873, 16/II/2002 (ALCB, CEPEC, HUEFS, K, RB). Mucugê, Capão do Correia, 2.200 m s.n.m., L.P. de Queiroz et al. 5634, 24/I/2000 (ALCB, CEPEC, HUEFS, SPF); estrada para o capão do Correia, campo rupestre, 1.264 m s.n.m, T.S. Nunes et al. 847 , 15/II/2002 (HUEFS); Serra do Gobira, 


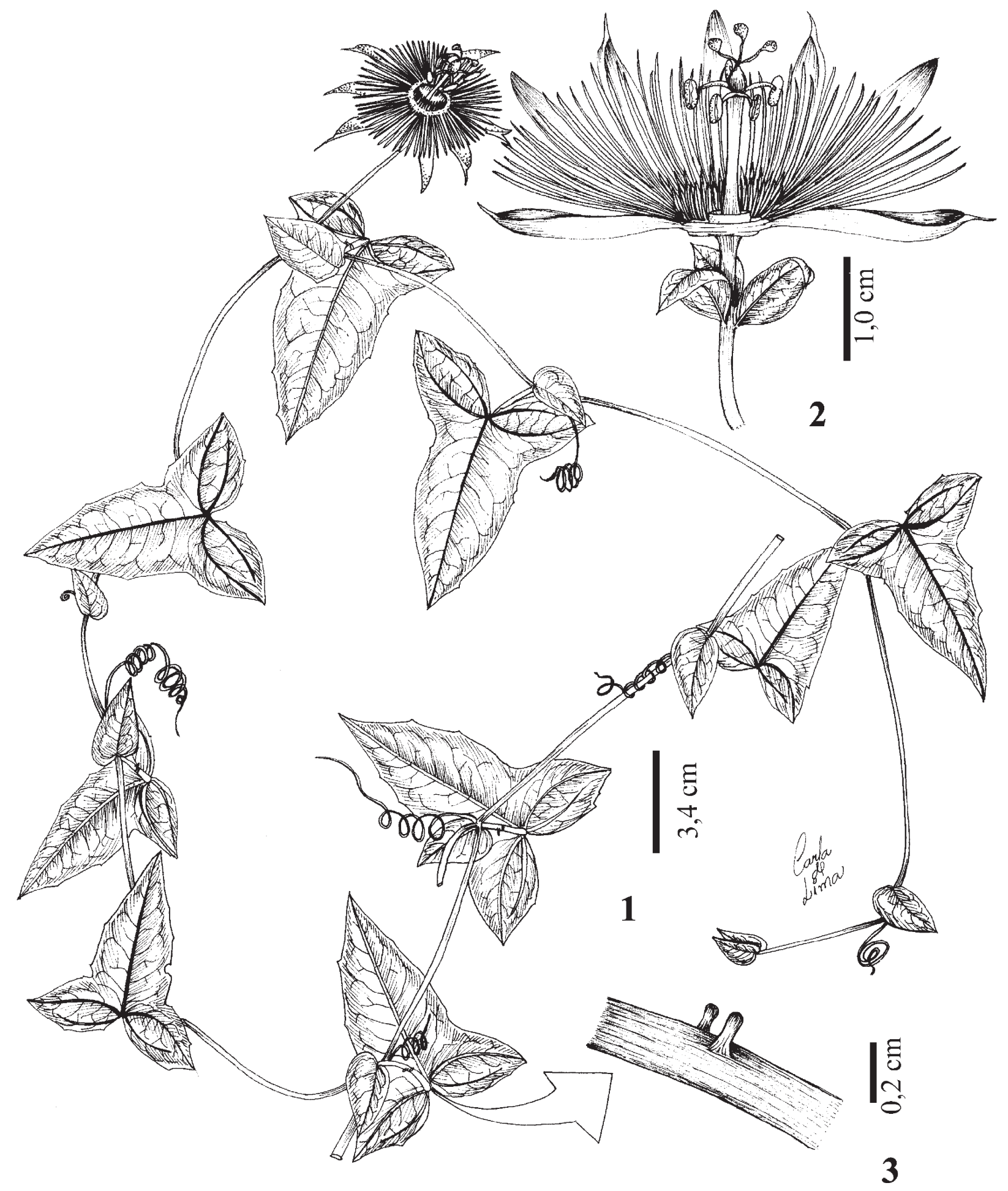

Figura 1. Passiflora mucugeana T.S. Nunes \& L.P. de Queiroz. 1. Hábito. 2. Flor em corte transversal. 3. Detalhe das glândulas no pecíolo (R.M. Harley 53589). 
1.471-1.568 m s.n.m., J.G.A. Nascimento et al. 334, 21/I/2005 (HUEFS).

\section{Agradecimentos}

Os autores desejam manifestar seus agradecimentos ao Dr. Armando Carlos Cervi (Universidade Federal do Paraná), Dr. Cássio van den Berg (Universidade Estadual de Feira de Santana) e à Dra. Daniela C. Zappi (Royal Botanic Garden - Kew), pelo incentivo e revisão deste trabalho; ao Conselho Nacional de Desenvolvimento Científico e Tecnológico, pela Bolsa de Produtividade em Pesquisa do segundo autor; ao curador do herbário RB (Jardim Botânico do Rio de Janeiro), pelo empréstimo do material.

\section{Referências bibliográficas}

Cervi, A.C. 1997. Passifloraceae do Brasil. Estudo do gênero Passiflora L., subgênero Passiflora. Fontqueria 45: $1-92$.

Feuillet, C. \& MacDougal, J.M. 2003. A new infrageneric classification of Passiflora L. (Passifloraceae). Passiflora 14(1): 34-38.

Killip, E.P. 1938. The American species of Passifloraceae. Publications Field Museum of Natural History, Botanica Serries 19(1-2): 1-613.

Nunes, T.S. \& Queiroz, L.P. de 2006. Flora da Bahia: Passifloraceae. Sitientibus 6(3): 194-226.

Sacco, J.C. 1966. Contribuição ao estudo das Passifloraceae do Brasil II. Duas novas espécies de Passiflora. Sellowia 18(18): 41-48.

Ulmer, T. \& MacDougal, J.M. 2004. Passiflora: Passionflowers of the world. Timer Press, Inc. Cambridge. 